\title{
Custo por Aluno: Uma Comparação Entre UFSC e Unisul
}

\author{
Cost Per Student: A Comparison of UFSC and Unisul
}

\author{
Thiago Coelho Soares \\ Mestre em Administração (UFSC) \\ Professor da Universidade do Sul de Santa Catarina (Unisul)
}

Mestre em Administração pela Unisul

Analista Acadêmica da Unisul

\author{
Pedro Antônio de Melo \\ Doutor em Engenharia da Produção (UFSC) \\ Professor do Programa do Pós-graduação em \\ Administração (UFSC)
}

\begin{abstract}
Resumo
O objetivo deste artigo consiste em comparar o custo por aluno da UFSC e da UNISUL conforme duas metodologias, a que leva em consideração os custos totais da universidade e a que utiliza apenas os gastos com educação. Para isso, foram feitas pesquisas documentais em demonstrativos contábeis, relatórios de gestão e previsões orçamentárias das universidades. Os resultados encontrados na pesquisa nos dão conta que o custo por aluno na UFSC foi maior do que na Unisul. Isso se deve pela influência de três fatores: 1. A educação como sistema público de ensino é um direito constitucional de todo cidadão brasileiro e que não mantém uma relação direta custo-benefício; 2. A grande quantidade de atividades de pesquisa e extensão; e 3. A titulação dos professores. Embora o tema custo por aluno seja considerado muito importante pelos dirigentes entrevistados de ambas universidades, cada uma destas trabalha de maneira diferente o assunto. A Universidade Federal de Santa Catarina utiliza a metodologia do TCU. Assim, o valor do custo do aluno acaba servindo de diretriz para o planejamento institucional. Em contrapartida, na Unisul o custo do aluno é calculado para cada curso, assim, estes apresentam um valor de crédito diferenciado, e este valor é utilizado para definir o valor das mensalidades cobradas.
\end{abstract}

Palavras chave: custo do aluno, universidade, financiamento do ensino superior.

\section{Abstract}

This paper is to compare the cost per student at UFSC and UNISUL as two methodologies, which takes into account the total costs of the university and to use only education spending. For this, research was done documentary on financial statements, management reports and budget forecasts of universities. The findings of the survey give us account that the cost per student at UFSC was higher than in Unisul. This is due to the influence of three factors: 1. Education as a public school system is a constitutional right of every citizen of Brazil and that does not maintain a direct cost-benefit analysis 2. The large amount of research and extension activities, and 3. Titration of teachers. Although the issue cost per pupil is considered very important by the leaders interviewed from both universities, each of these works the matter differently. The Federal University of Santa Catarina using the methodology of TCU. Thus, the value of the cost of the student ends up serving as a guideline for institutional planning. By contrast, in Unisul the cost of the student is calculated for each course, so they present a different credit value and this value is used to set the value of tuition charged.

Keywords: cost of the student, university, higher education financing. 


\section{INTRODUÇÃO}

A universidade é caracterizada pela indissociabilidade entre as funções de ensino, pesquisa e extensão. Este tripé proporciona o desenvolvimento da educação e por conseqüência da sociedade onde estas universidades estão inseridas. Porém, uma universidade que apresentar a pesquisa e a extensão de forma mais robusta acaba gerando um gasto maior, o que por conseqüência gerará um custo por estudante mais elevado também.

Segundo Barba (2005) a verdadeira função da universidade é desenvolver meios para que alunos, professores e técnicos possam construir o conhecimento apreendendo a construir responsabilidades no aprimoramento do Ensino, da Pesquisa e da Extensão para a construção de uma cidadania mais justa e equilibrada em nossa sociedade.

De uma maneira mais aprofundada Melo (2002) afirma que nos dias atuais, o grau de complexidade das atividades desenvolvidas pela instituição universitária, adquire proporções inimagináveis para uma parcela significativa da população, que se acostumou, ao longo do tempo, a enxergar apenas uma das suas funções mais visíveis que é a de formadora de recursos humanos para o mercado de trabalho. Mas esta função é apenas uma, entre as tantas desempenhadas pela instituição, como conhecimento, ciência, tecnologia, arte, cultura, identidade, riqueza material e valores, e isto não está beneficiando apenas o diplomado, mas a sociedade como um todo.

A nomenclatura adotada nesta pesquisa para a diferenciação dos custos existentes é a mesma apresentada por Amaral (2002). Assim, a metodologia que leva em consideração o custo total da universidade dividido pela quantidade total de estudantes é denominada custo por estudante. Já a metodologia que considera apenas o custo que a instituição tem com ensino, dividido pela quantidade total de alunos é denominada o custo do aluno.

A história da Fundação Universidade do Sul de Santa Catarina - Unisul começa em 1964, na cidade de Tubarão, com a criação da Faculdade de Ciências Econômicas do Sul de Santa Catarina, aprovada pela Lei Municipal n. 353, de 25 de novembro de 1964, que se vinculou ao Instituto Municipal de Ensino Superior - IMES, criado pela Lei n. 355, de 10 de dezembro de 1964. Em 1989, a Universidade do Sul de Santa Catarina (Unisul) foi criada pela Lei Municipal aprovada pela Câmara de Vereadores, sancionada pelo Prefeito Municipal e reconhecida pelo Parecer n. 28/89 do Conselho Federal de Educação, homologado pelo Ministro da Educação, por intermédio da Portaria n. 028, de 27 de janeiro de 1989. Hoje a universidade possui cinco campi, o campus em Tubarão, onde esta situada a Reitoria da universidade, os demais em Araranguá, Içara, Palhoça e Florianópolis.

A outra universidade analisada foi a Universidade Federal de Santa Catarina - UFSC que foi fundada em 1960, a partir da reunião das faculdades de Medicina, Direito, Farmácia, Odontologia, Filosofia,Ciências Econômicas, Serviço Social e escola de Engenharia Industrial. No início eram apenas 800 alunos. Hoje, passados 46 anos a UFSC possui mais de 32.000 , sendo cerca de 18 mil alunos na graduação e nos de pós-graduação lato sensu, mais de 3 mil alunos. Nos programas stricto sensu em nível de mestrado -6.000 alunos e no doutorado -1.700 alunos.

Assim, esta pesquisa teve por finalidade fazer um estudo comparativo do custo do aluno e do custo por estudante entre a Universidade Federal de Santa Catarina - UFSC e a Universidade do Sul de Santa Catarina - UNISUL.

De forma coerente com o descrito acima, o problema de pesquisa deste trabalho pode ser assim definido: "Qual a diferença entre os custos do aluno e por estudante na UFSC e UNISUL nos anos de 2003 e 2004?"

O objetivo geral deste artigo consiste em comparar o custo por aluno da UFSC e UNISUL conforme duas metodologias: a que leva em consideração os custos totais da universidade (gera o custo por estudante) e a que utiliza apenas os gastos com educação (que gera o custo do aluno).

Para o alcance do objetivo geral deste estudo elaborou-se os seguintes objetivos específicos: 
- Identificar os custos totais de cada universidade;

- Identificar os custos com educação de cada universidade;

- Identificar o número de alunos de cada universidade;

- Calcular o custo por aluno e o custo por estudante de cada universidade;

- Comparar os custos por aluno e os custos por estudante;

- Explicar as diferenças existentes entre os custos encontrados.

Segundo Morgan (2003) as instituições de ensino possuem características diferentes com relação às outras empresas como ainda empregarem maciça mão-de-obra, o que caracteriza um ponto divergente entre a estrutura de custos das instituições de ensino superior e as empresas industriais. E por este motivo se faz a necessidade de um estudo diferenciado e mais aprofundado dos custos em universidades.

Esta pesquisa se justifica na medida em que os estudos nesta área ainda são insipientes e muito controversos. Além disso, neste trabalho procurou-se fazer uma comparação entre uma universidade pública federal e uma universidade privada comunitária. Esta comparação servirá para mostrar as diferenças que existe no valor do custo por aluno e na aplicação das metodologias existentes.

Mais especificamente, pretende-se comparar os valores encontrados, entre as metodologias expostas, a fim de estabelecer padrões de comparação entre estas universidades.

O estudo de caso comparativo segundo Bruyne, Herman e Schoutheete (1991) procura evidenciar os contrastes entre várias organizações cujas semelhanças e dessemelhanças são analisadas.

A pesquisa quanto aos fins pode ser considerada descritiva. É descritiva, pois descreve as informações obtidas por meio da pesquisa documental, dos balanços das universidades pesquisadas referentes aos valores financeiros necessários para calculo o custo do aluno e por estudante. Além, de descrever informações obtidas nas entrevistas com os dirigentes das universidades. Porém, é explicativa também, pois procurou-se explicar o porque dos contrastes encontrados nos custos por estudantes gerados.

Quanto aos meios de investigação, este trabalho foi dividido em duas etapas, uma inicial que foi a pesquisa bibliográfica, e outra final que foi a pesquisa documental e entrevistas.

Yin (2001) afirma que a documentação é uma fonte estável de coleta de dados, tendo em vista que pode ser revista inúmeras vezes, além de ser exata por conter nomes, referências e detalhes como também possui uma ampla cobertura, pois abrange longos períodos de tempo e espaço. Porém, o autor ressalta que o acesso aos documentos pode ser dificultoso e caso não seja realizado uma pesquisa completa pode tendênciar a pesquisa. Na pesquisa documental foram analisados demonstrações contábeis das universidades, a fim de municiar o investigador de informações financeiras, sendo estas informações necessárias para o cálculo do custo do aluno e a custo por estudante.

Foram entrevistados na UFSC o pró-reitor de ensino e o responsável pelo Programa Integrado de Planejamento. Já na UNISUL, os entrevistados foram o diretor do campus da grande Florianópolis e o responsável pelo projeto de custo da instituição.

Foi feito um corte transversal, sendo analisados somente os anos de 2003 e 2004.

\section{CUSTO POR ALUNO NA EDUCAÇÂO SUPERIOR}

Segundo Morgan (2003) as instituições de ensino superior possuem características diferentes com relação às outras empresas. Estas instituições possuem a característica de ainda empregarem maciça mão-de-obra, o que caracteriza um ponto divergente entre a estrutura de custos das instituições de ensino superior e as empresas industriais. E por este motivo se faz a necessidade de um estudo mais aprofundado dos custos em universidades

Conforme os autores Cruz, Diaz e Luque (2003) existem muitos desacordos em relação às estatísticas e metodologias de orçamentos e de custos em instituições de ensino superior. 
Para Amaral (2002) o estudo de custos no ensino superior é revestido de complexidade, porque é possível elaborar uma infinidade de metodologias. Outra complexidade citada pelo autor é que essa infinidade de metodologias pode gerar comparações irreais entre os custos de alunos de diferentes instituições nacionais ou de diferentes países.

Segundo Lobo e Filho (2004) na maioria dos países, e o Brasil não é exceção, o custo direto do ensino é cerca de um terço dos gastos de uma Instituição de Ensino Superior (IES), que incluem administração, biblioteca, esporte, transporte, segurança, manutenção, gestão acadêmica, investimentos, impostos (em alguns casos) etc. - sem falar nos gastos que algumas com pesquisa e extensão. E complementam dizendo que uma universidade que pesquisa custa mais caro por aluno do que uma instituição voltada somente ao ensino.

Amaral (2002) afirma que o custo do aluno significa o volume de recursos financeiros que as instituições utilizam na formação do seu corpo discente. Assim, três decisões sociais interferem neste tipo de custo: o total gasto na educação superior, o número de unidades de serviço disponibilizadas e o nível da qualidade. $O$ autor chama a atenção para o custo do estudante, que é o que mais aparece nas discussões sobre custos do aluno no Brasil. Esta metodologia divide o volume total de recursos aplicados na instituição pelo número total de alunos.

Conforme Cafardo e Souza (2004) o Tribunal de Contas da União (TCU) calcula os custos dos estudantes, das instituições de ensino federais, a partir dos gastos realizados pelas instituições. Para o tribunal não faz diferença se as despesas são com atividades de ensino ou outras executadas pela instituição de ensino superior, como prestação de serviços e programas de extensão, por exemplo. Segundo Morgan (2003) o TCU realiza assim o cálculo:

- Soma as despesas correntes da universidade.

- Depois subtrai $65 \%$ das despesas correntes do hospital universitário, aposentadorias e reformas, pensões, sentenças judiciais, despesa com pessoal cedido - docente e técnico-administrativo, despesa com afastamento País/Exterior - docente e técnico-administrativo.

- Assim, no final divide pela quantidade de alunos para saber o custo por aluno que a instituição apresenta.

Neste artigo leva-se em consideração as duas metodologias sugeridas por Amaral (2002). A primeira é o custo do estudante. Esta metodologia divide o volume total de recursos aplicados na instituição pelo número total de alunos. A segunda metodologia é denominada da seguinte forma pelo autor: custo por aluno, que significa o volume de recursos financeiros que as instituições utilizam na formação do seu corpo discente.

Ainda segundo o autor, as instituições, principalmente federais, de ensino superior possuem despesas que não se dirigem diretamente ao ensino, à pesquisa e à extensão. Porém, em muitos casos estes valores são incorporados na hora do cálculo. Assim, quando incorporados geram o custo por estudante.

Conforme Kraemer (2004) o cálculo de custo por aluno permite uma maior visibilidade do processo de formação do próprio custo da universidade, assim pode tornar mais claro as diferentes áreas envolvidas em cada atividade (ensino, pesquisa e extensão) e como as áreas de apoio contribuem com estes custos.

Amaral (2002) alerta que as instituições federais de ensino superior mantêm hospitais universitários, uma grande quantidade de serviços de assistência à população carente, bibliotecas comunitárias, orquestras e museus, entre outras atividades, além do pagamentos de aposentados e precatórios. Assim, o valor que estas instituições despedem para a manutenção destas atividades acarreta em uma distorção nos custos do aluno. Por isto, é necessário cuidado especial na hora de comparar os custos do aluno entre instituições de ensino superior, de uma maneira geral.

Conforme observado acima, é necessário conhecimento dos custos de uma universidade para saber quanto ela gasta com um aluno e, assim, tentar eliminar desperdícios oriundos da incorreta utilização dos recursos financeiros. 


\section{APRESENTAÇÃO DOS RESULTADOS}

Neste item, faz-se uma análise descritiva do custo por aluno na UFSC e na UNISUL. Aqui são apresentadas informações colhidas nos demonstrativos contábeis das duas universidades e nas entrevistas com os dirigentes. Inicialmente, apresenta-se os valores encontrados nas duas metodologias a serem utilizadas e posteriormente faz-se comentários acerca dos valores encontrados.

\begin{tabular}{|l|l|l|}
\hline $\mathbf{2 0 0 3}$ & UNISUL $^{\mathbf{1}}$ & UFSC $^{\mathbf{2}}$ \\
\hline Graduação & 17.673 & 18.714 \\
\hline Pós-graduação & 2.440 & 10.869 \\
\hline Total & $\mathbf{2 1 . 4 8 4}$ & $\mathbf{3 2 . 9 1 1}$ \\
\hline $\mathbf{2 0 0 4}$ & & \\
\hline Graduação & 18.323 & 18.587 \\
\hline Pós-graduação & 2.439 & 7.384 \\
\hline Total & $\mathbf{2 3 . 6 0 4}$ & $\mathbf{3 2 . 4 8 5}$ \\
\hline
\end{tabular}

Quadro 1 - Quantidade de alunos em 2003 e 2004

Fonte: 1 - ACAFE (2005); 2 - UFSC (2005)

A quantidade de alunos nas duas instituições de ensino superior é importantíssima, pois sem esta informação não será possível calcular o custo do aluno e o custo por estudante. Pode-se observar que houve um acréscimo na quantidade de discentes na UNISUL e um decréscimo na UFSC.

\begin{tabular}{|l|l|l|}
\hline $\mathbf{2 0 0 3}$ & UNISUL $^{\mathbf{1}}$ & UFSC $^{\mathbf{2}}$ \\
\hline Despesas (por ano em R\$) & 135.787 .850 & 222.512 .986 \\
\hline Despesas com ensino (por ano em R\$) & 75.291 .689 & 171.551 .264 \\
\hline $\mathbf{2 0 0 4}$ & & \\
\hline Despesas (por ano em R\$) & 150.972 .916 & $270.093 .721^{1}$ \\
\hline Despesas com ensino (por ano em R\$) & 86.273 .397 & 196.491 .440 \\
\hline
\end{tabular}

Quadro 2- Despesas das universidades em 2003 e 2004

Fonte: 1 - UNISUL (2005); 2 - UFSC (2005)

Os valores do quadro 2 foram extraídos dos demonstrativos contábeis da Unisul e dos relatórios de gestão e dos orçamentos da UFSC. A despesa de cada instituição é o valor correspondente ao total de gastos durante o ano base citado. Já as despesas com o ensino são as despesas alocadas com a finalidade de realizar as atividades de ensino na graduação e pósgraduação.

A UFSC não possui um sistema próprio para calcular o Custo por Aluno. Para cumprir determinação do Tribunal de Contas da União - TCU - na parte referente ao Relatório de Gestão, no qual contém um capítulo sobre indicadores do TCU, existe um item que mostra a aplicação da metodologia de custo por aluno, desenvolvida pelo próprio TCU, e que é aplicada em todas as universidades públicas brasileiras. Como no Relatório de Gestão, a Universidade obrigatoriamente precisa responder a aplicação desta metodologia. Quando se considera o Modelo do TCU como a "Metodologia de Custo por Aluno", o setor responsável pela elaboração do Relatório de Gestão é o Programa Integrado de Planejamento, unidade esta vinculada ao Gabinete do Reitor.

A Unisul calcula o custo por aluno separadamente para cada curso. A partir das necessidades financeiras apresentadas nos projetos curriculares, é calculado o custo do crédito para cada curso. Com base neste valor é que as mensalidades têm seu preço definido. Independentemente, se o curso apresenta disciplinas que necessitam de laboratório e outras não, o valor do crédito é o mesmo para todas estas disciplinas. Assim, cada curso apresenta um valor

\footnotetext{
${ }^{1}$ Custo Corrente - Segundo Metodologia do TCU
} 
de crédito diferenciado, a partir dos custos indicados nos projetos curriculares. Este cálculo é realizado pelo Departamento Contábil da universidade.

\begin{tabular}{|l|l|l|l|}
\hline $\mathbf{2 0 0 3}$ & UNISUL & UFSC & \% linha \\
\hline Custo por estudante (por ano em R\$) & 6.320 & 6.761 & $93,48 \%$ \\
\hline Custo do aluno (por ano em R\$) & 3.505 & 5.212 & $67,25 \%$ \\
\hline$\%$ coluna & $55,46 \%$ & $77,09 \%$ & \\
\hline
\end{tabular}

Quadro 3- Custo por estudante e do aluno em 2003

Fonte: Elaborada pelos autores.

A partir dos dados do quadro 3, que mostra os valores a partir das duas metodologias aplicadas nesta pesquisa, pode-se observar que o custo do aluno em 2003 na Unisul correspondeu a $55,46 \%$ do custo por estudante. Na UFSC este percentual foi de $77,09 \%$. Os valores encontrados mostram que, embora o custo do aluno seja maior na UFSC, proporcionalmente os gastos com ensino são mais próximos dos gastos totais da universidade. Vale ressaltar que o valor utilizado como custo total da universidade foi o custo corrente. $\mathrm{Na}$ Unisul existiu uma diferença muito maior entre os valores encontrados. Isto leva a acreditar que os custos com ensino são proporcionalmente menores nesta instituição de ensino superior. Outra observação importante é que o custo do aluno na Unisul representa 67,25\% do custo do aluno da Universidade Federal de Santa Catarina.

\begin{tabular}{|l|l|l|l|}
\hline $\mathbf{2 0 0 4}$ & UNISUL & UFSC & \% linha \\
\hline Custo por estudante (por ano em R\$) & 6.396 & 8.314 & $76,93 \%$ \\
\hline Custo do aluno (por ano em R\$) & 3.655 & 6.048 & $60,43 \%$ \\
\hline$\%$ coluna & $57,14 \%$ & $72,74 \%$ & \\
\hline
\end{tabular}

Quadro 4- Custo por estudante e do aluno em 2004

Fonte: Elaborada pelos autores.

Verifica-se que o ano de 2004 não foi muito diferente do anterior. Observar-se que o custo do aluno na Unisul correspondeu a 57,14\% em relação ao custo por estudante. Na UFSC este percentual foi de $72,74 \%$. Ambos valores induzem a reflexão que embora o custo do aluno seja maior na Universidade Federal de Santa Catarina, proporcionalmente os custos com ensino são mais próximos dos gastos totais da universidade. É importante relembrar que o valor utilizado como custo total da universidade foi o custo corrente. Na Unisul existiu uma diferença muito maior entre os valores encontrados. Portanto, pode-se aferir que os custos com ensino são proporcionalmente menores. É importante ressaltar também, que o custo do aluno na Unisul representa $60,43 \%$ do custo do aluno da UFSC.

\begin{tabular}{|l|l|l|}
\hline$(\mathbf{2 0 0 4 / 2 0 0 3 ) x 1 0 0}$ & UNISUL & UFSC \\
\hline Custo por estudante & $1,2 \%$ & $22,87 \%$ \\
\hline Custo do aluno & $4,28 \%$ & $16,04 \%$ \\
\hline
\end{tabular}

Quadro 5 - A evolução dos custos nas universidades

Fonte: Elaborada pelos autores.

Com relação ao quadro 5, observa-se que o aumento no custo se deu de forma muito mais acentuada na UFSC do que na Unisul. Na primeira o aumento do custo do aluno foi de $16,04 \%$. Já na segunda, este aumento foi de 4,28\%

Os cálculos de custo por aluno são feitos na UFSC para atender a uma determinação do TCU, que é utilizado para estabelecer comparativos de atividades entre as universidades públicas federais. Já na Unisul, este cálculo é feito para definir o valor dos créditos a serem cobrados em cada curso, e por conseqüência, o valor das mensalidades.

$\mathrm{O}$ assunto custo por aluno foi considerado importante nas duas universidades pesquisadas. Na UFSC serve como diretriz para um planejamento institucional, no sentido de 
compreender a dinâmica institucional, inclusive para a ampliação e ocupação de vagas públicas. $\mathrm{Na}$ Unisul, este assunto é de fundamental importância. Isso porque os valores oriundos das mensalidades são utilizados para cobrir os custos/ despesas do ensino. Assim, os projetos de pesquisa e extensão apresentam fontes de financiamento diferentes. Por isso, se o cálculo do custo por aluno não for realizado de forma satisfatória a universidade pode acabar tendo prejuízos com o curso em questão.

Quando o assunto é a fonte financeira que supre estes gastos as duas universidades apresentam fontes diferentes. Na UFSC o custo aluno é calculado através dos recursos financeiros oriundos diretamente do Tesouro Nacional, e de recursos oriundos a partir de Convênios geradores de projetos, que juntos compõem a dotação orçamentária da Universidade. Já na Unisul o custo com o ensino é totalmente coberto com o valor arrecadado com as mensalidades. Assim, as despesas de pesquisa e extensão têm outras fontes de financiamento.

\section{CONCLUSÃO}

Para o entendimento do porquê das diferenças no valor do custo do aluno requer entendimento de que a educação como sistema público de ensino é um direito constitucional, de todo cidadão brasileiro. Assim, a educação como bem público não mantém uma relação direta custo-benefício, mas necessariamente uma compreensão de investimento e desenvolvimento social.

Uma outra justificativa diz respeito a indissociabilidade entre as atividades de ensinopesquisa-extensão. Estas atividades somente são articuladas e desenvolvidas em todas as áreas do conhecimento e cursos ofertados nas instituições públicas. Aqui novamente a relação custo da hora atividade do professor não poderá ser indicada somente pelo trabalho de sala de aula. Nas universidades públicas o professor possui condições de desenvolver simultaneamente as atividades de ensino-pesquisa e extensão, e é justamente nesta articulação, que o processo de ensino se qualifica com excelência pelas condições requeridas. Contudo, estas afirmações estão inseridas num contexto de responsabilidade da gestão e dos investimentos dos recursos públicos. É a grande quantidade de professores que se dedicam integralmente nas universidades federais. O MEC estipula um número mínimo de $30 \%$ de professores de tempo integral. As universidades federais apresentam uma quantidade bem acima deste valor, o que gera um aumento de custo, tendo em vista que normalmente estes professores de tempo integral não têm mais do que oito horas semanais de aulas na graduação. $\mathrm{O}$ restante deste tempo estes profissionais dedicam aos cursos stricto sensu e aos núcleos de pesquisa. Assim, as universidades federais necessitam ter mais professores para poderem estar preenchendo o quadro de disciplinas na graduação.

Um terceiro ponto importante a ser ressaltado é a grande quantidade de professores com titulação stricto sensu. O MEC determina um valor mínimo de $30 \%$ de professores mestres ou doutores nas universidades. Como as universidades federais têm esse número bem mais elevado, acaba tendo um valor com salários maiores, tendo em vistas que estes profissionais recebem salários superiores aos que não têm esta titulação stricto sensu. Na UFSC, cerca de $93 \%$ dos professores são mestres ou doutores.

Então, pode-se observar que, embora o tema custo por aluno seja considerado muito importante pelos dirigentes entrevistados, cada universidade tem um foco diferente na utilização deste valor. A UFSC, utiliza-se de uma metodologia imposta pelo TCU e o valor do custo do aluno acaba servindo de diretriz para um planejamento institucional. Já na Unisul, o custo do aluno é calculado de forma independente nos diversos cursos. Assim, cada curso apresenta um valor de crédito diferenciado, e este valor é utilizado para definir o valor das mensalidades cobradas pela universidade. 


\section{REFERÊNCIAS}

ACAFE. Estatística das instituições afiliadas. Disponível em:

$<$ http://www.acafe.org.br/newpage/index.php?endereco=boletim/ies.php> Acesso em: 05 de abr. 2009.

AMARAL, Nelson Cardozo. O custo do aluno: uma metodologia para as IFES. Doxa: revista semestral do unilesteMG, Coronel Fabriciano, MG : v. 4, n. 8, p. 49-64, jul/dez. 2002.

BARBA, Clarides Henrich de. A função da universidade na educação. Disponível em: $<$ http://www.unir.br/ albertolinscaldas/funcaodauniversidade.htm>. Acesso em: 12 de abr. de 2009.

BRUYNE, Paul de; HERMAN, Jacques; SCHOUTHEETE, Marc de. Dinâmica da pesquisa em ciências sociais: os polos da pratica metodológica. 5a ed. Rio de Janeiro: F. Alves, 1991.

CAFARDO, Renata; SOUZA, Marcus de Moura e. MEC já contaria com 50 mil vagas para 'estatizar'. O Estado de São Paulo -19/2/2004.

KRAEMER, Maria Elisabeth Pereira. O Custeio Baseado em Atividades e sua eficiência em Instituições de Ensino Superior. IV Colóquio de gestão universitária, Florianópolis, 2004.

LOBO, Roberto Leal; FILHO, Silva. Números que confundem. Revista Carta Capital. 28 de abr. de 2004.

MELO, Pedro Antônio de. A Cooperação Universidade/Empresa nas universidades públicas brasileiras, Tese (Doutorado em Engenharia da Produção) Programa de Pós-graduacao em Engenharia de Produção, Universidade Federal de Santa Catarina, 2002.

MORGAN, Beatriz Fátima. Universidade de Brasília. A determinação do custo do ensino na educação superior: o caso da universidade de Brasília. Brasília, 2003. Dissertação (mestrado) Universidade de Brasília.

UNIVERSIDADE FEDERAL DE SANTA CATARINA - UFSC. Boletim de dados. Disponível em:

$<$ http://www.pip.ufsc.br/doc/BOLETIM\%20DE\%20DADOS/2004/BOLETIM\%20DE\%20DAD OS\%202004_cd.pdf> Acesso em: 22 de set. 2009.

2009.

. Relatório de gestão. Disponível em: <http://www.pip.ufsc.br/> Acesso em: 02 de mar.

UNIVERSIDADE DO SUL DE SANTA CATARINA - UNISUL. Demonstrações contábeis. Disponível em: <http://www.unisul.br/index.pfm?codpagina=562> Acesso em: 22 de jun. 2009.

YIN, Robert. Estudo De Caso: Planejamento e Métodos. Porto Alegre: Bookman, 2001. 